\title{
Shifting the academic lens: Development of an interdisciplinary Indigenous health nursing course
}

\author{
Sheila Y. Blackstock *1,2 \\ ${ }^{1}$ School of Nursing, University of Alberta, Edmonton, Alberta, Canada \\ ${ }^{2}$ School of Nursing, Thompson Rivers University, Kamloops, British Columbia, Canada
}

Received: May 5, 2016

DOI: $10.5430 /$ jnep.v7n1p11
Accepted: July 31, 2016

Online Published: August 17, 2016

\begin{abstract}
In Canada, Truth and Reconciliation Commissions Calls to Action (2015) calls on nursing schools to requires in part, all students to take Aboriginal health issues inclusive of the history and legacy of residential schools, Aboriginal rights and Indigenous teachings and practices (TRC, 2015, p.3). Further, the TRC calls upon governments to increase the number of Aboriginal professionals working in the health-care field. The development of an interdisciplinary Indigenous health nursing course was timely in response to the TRC Calls to Action (2015) and an opportunity to weave interdisciplinary tenets of western nursing ontologies and epistemologies with Indigenous ways of knowing and being into a shared tapestry to insure future sustainability of health services and has secondary impacts on nursing recruitment and retention. Honoring protocols, engagement of Aboriginal Peoples through lessons learnt in northern, rural roots, partnerships and embracing a student-centered teaching pedagogy prompts a shift in the academic lens.
\end{abstract}

Key Words: Canada, Registered nurses, Interdisciplinary, Indigenous health, Othering, Two-eyed seeing, Student-centered teaching pedagogy, Curriculum development

\section{INTRODUCTION}

The Truth and Reconciliation Calls to Action $(2015)^{[1]}$ challenges universities to provide aboriginal course content to improve student's knowledge and abilities to positively impact Indigenous health status outcomes and has relevance to informing nursing curriculum. The development of Indigenous curriculum and courses within Schools of Nursing built on partnerships, relationships and engagement of Aboriginal communities through respectful protocols are needed ${ }^{[2]}$ to insure sustainability of health services, partnerships with Aboriginal communities, and has secondary impacts on nursing recruitement and retention.

The process of developing an Indigenous health course is re- viewed to offer insights into an introduction of allied health, paraprofessionals and nursing students to Indigenous Peoples health in Canada. (The term Indigenous has a global meaning and is often used to refer to the First Peoples of any region or country. The term Aboriginal peoples refer to First Nations, Inuit and Métis persons of Canada as defined by the Canadian Constitution Act, 1982. The term Aboriginal and Indigenous is used in this paper to include all categories of Indigenous Peoples of Canada. The term peoples, reminds us that there are many different Indigenous cultures.) In particular, Indigenous ways of knowing and being in the context of holistic health (A First Nations Holistic Policy and Planning Model (AFN, 2013). A Health Model in-

\footnotetext{
*Correspondence: Sheila Y. Blackstock; Email: sblackst@ualberta.ca; Address: School of Nursing, University of Alberta, Edmonton, Alberta, Canada.
}

Published by Sciedu Press 
forms the conceptualization of Indigenous health. The model acknowledges: the disproportion of health status of First Nations people compared to most Canadians; self-governance and builds on the medicine wheel approach; includes environmental health, sustainable development, cultural and social elements as key tenets to reframe health inequities among Aboriginal Peoples.). Indigenous ways of knowing and health are the foundation of knowledge pedagogy for future allied health, social workers, and nurses learn to 'reflexively' ${ }^{[3]}$ relate social-cultural, historical and contextual determinants of health among Aboriginal Peoples. ${ }^{[4]}$ The development of the course sought to integrate Indigenous ways of knowing through a decolonization framework that engages local knowledge, methodologies and practices of Indigenous Peoples and provides students with an environment to engage in experiential, reflexive learning ${ }^{[3]}$ informed by local Knowledge Keepers. The theoretical approach to the course embraces the pedagogy of Indigenous Knowledge on the one hand and on the other hand uses the premise of 'twoeyed seeing' (Learning to see from one eye with the strengths of [or best in] Indigenous knowledge and ways of knowing, and learning to see from the other eye with the strengths of [or best in] Western knowledge and ways of knowing... and most importantly, using both eyes together for the benefit of all. $)^{[4,5]}$ of coalescing of the student's respective western, allied health, social work or nursing, knowledge and methodologies while honoring traditional ways of knowing and being of Indigenous cultures.

In particular, this premise of two-eyed seeing has personal meaning as a Gitanmaax member seeking to find balance between nursing practice and academia amongst western knowledge and methodologies while continuing my journey of learning Indigenous ways of knowing and being whilst processing my personal experiences of 'othering'. Journeys hold real personal meaning as an academic but also as a reflection of my personal ways of knowing through being situated and constituted by rural, northern living and landscapes. Being situated in a family that lived in rural Northern British Columbia (BC). Northern BC wild landscapes and terrains paint a canvas of a calming presence yet brings many diverse challenges; limited access to health and social services, supports, resources; a lack of culturally appropriate services; and a need to establish strong local food systems are just a few of the obstacles to achieving better health outcomes in communities and are further multiplied in Aboriginal communities. Communities in which being community minded/neighbourly is a holistic approach; a way of knowing and being. The holistic approach becomes a part of the constitution of a northerner which embraces a consideration of the well-being of others not only essential to survival but often is required to sustain oneself-a spirit of reciprocity is a way of being-the counter argument to 'othering'; judging or determining to what degree individuals are Aboriginal or not. The northerner perspective of inclusiveness and well-being of others brings me solace and hope that 'othering' scars will be healed and the behavior of 'othering' will be extinct. Sustainability of self in terms of supporting one another during inclement conditions, inequities, inequalities in access to services and through relationships that offer emotional and spiritual support. The personal journey provides a foundation, a guide, a lens to approach the opportunity and honour of developing an interdisciplinary indigenous health course.

The journey centers around being in Aboriginal communities as a nursing lecturer, community member building partnerships to inform the course development on the one hand and on the other hand involving student nurses in the process informed by Context-Based Learning (C.B.L.). ${ }^{[6]}$ The impacts of a student centered, ${ }^{[7]}$ interdisciplinary approach ${ }^{[8]}$ extend beyond the lecture halls and into Indigenous communities wherein nursing students explore an interprofessional framework (Interprofessional collaboration for the purposes of this course is the process of developing and maintaining effective interprofessional working relationships with learners, practitioners, patients/clients/families and communities to facilitate optimal holistic health outcomes. Elements of collaboration include respect, trust, shared decision making, and partnerships.) of practice and immersed in aboriginal health organizations and communities to facilitate collaboration and planning of services to improve Indigenous health status.

\section{Problem statement}

When nursing students are not given the opportunity to learn how to practice cultural safety, a two-eyed seeing approach and knowledge of nursing practice within interdisciplinary teams in a collaborative manner it becomes a barrier to actualizing optimal Indigenous health outcomes. ${ }^{[9]}$ Further, when nursing students do not receive support to enact Intercollaborative practice (i.e., mix of para, health, social, non-professionals) when governed by administrators in Aboriginal health care organizations off reserve or on reserve, their scope of nursing practice becomes constrained within the health care setting and may lead to dissatisfaction and ultimately nurses leaving Aboriginal nursing practice areas where it is needed most. There is a gap in engaging with Indigenous communities to inform nursing curriculum to enact a decolonizing framework where nursing epistemology and ontology is informed by a two-eyed seeing and Intercollaborative practice approach. 


\section{BACKGROUND}

In British Columbia (BC), Canada, the signing of a Tripartite Framework Agreement on First Nation Health Governance ${ }^{[10]}$ between the federal, provincial government and the First Nations Health Authority (FNHA) mandated BC First Nations' full involvement in health program and service delivery and decision-making in the deliverance of health services. The agreement acknowledged the transfer of Federal Health Program to the FNHA along with the planning, design, management and delivery of First Nations health programs by the FNHA. Recently, the First Nations Health Authority (FNHA) Nursing Review ${ }^{[11]}$ recommendations from a review included in part: a) a shift in service model delivery that integrates Primary Care and Public Health in communities; b) Nursing Resource mix model that aligns with the interdisciplinary model and that optimizes the utilization of existing nursing resources; and c) further to realign the nursing services department to support an interdisciplinary model.

Interdisciplinary models present an opportunity for nurse educators to prepare student nurses for practice in Aboriginal communities. The integration of models that embrace the western ways of knowing familiar to the traditions of nursing education and Indigenous ways of knowing and being presents an opportunity for innovation in nursing education and practice. The integration of an interdisciplinary model and a two-eyed seeing approach to inform an Interdisciplinary Indigenous Health nursing course is timely given the Truth and Reconciliation Calls to Action ${ }^{[1]}$ and the literature supporting interdisciplinary collaborative practice, community involvement in curriculum development and theoretical approaches to use both western and Indigenous ways of being and knowing.

\section{Literature REVIEW}

Innovations in interdisciplinary collaborative practice approaches positively impact the health status of Indigenous communities and show promise with recruitment and retention of health professionals on the one hand and on the other hand serve as role models to potential First Nations students. ${ }^{[2]}$ Researchers have applied interprofessional approaches to curriculum development ${ }^{[2,6]}$ acknowledged the role, role expectation of paraprofessionals within rural and remote interdisciplinary nursing teams. ${ }^{[3]}$ Providing care in Aboriginal communities requires knowledge of interdisciplinary teams in theory, nursing practice and Indigenous knowledge. Indigenous knowledge is knowledge that is sacred to local Aboriginal Peoples and has meaning and relevance to nurses trained and practicing in Aboriginal communities. Curriculum developers should begin with cultural safety perspectives decentering power in relational practices to shift professional focus away from learning about cultural differences and focus the lens inward ${ }^{[12-14]}$ to understand how our assumptions, biases, situatedness and constitutedness, perspectives on health can be informed by Indigenous ways of being and knowing. When curriculum is developed through engagement, partnerships and honoring of protocols then CBL is enhanced and enacted in nursing practice rather than hastily developing curriculum in isolation from Indigenous Peoples.

A haste response to develop Indigenous curriculum content can result in tokenism in spite of authentic desire to truly enact a respectful response to the TRC Calls to Action. ${ }^{[1]}$ Tokenism has historically been the hiring of successful candidates who have Aboriginal ancestry into designated positions to "address racism" the marginal representation of Aboriginal Peoples in an organization. This was thought to address discrimination of Aboriginal Peoples where it actually resulted in the perception of the public of organizations hiring the "token Indian" to insure representation from Aboriginal communities. ${ }^{[14]}$ Further, enacting a respectful response means the development of curriculum by academics and nursing faculty utilizing a decolonizing framework and reflexivity to engage Aboriginal communities requires time to insure that protocols are followed. Time viewed through an Indigenous Ways of knowing and being lens(es) to build partnerships, engage protocols and honoring of knowledge keepers which may not reconcile with the Western academia allotment of faculty workload credits, educational program development committees, course development deadlines inherent within most academic institutions. Reconciliation of academic processes that require protocols to be followed and support academics through enacting consideration of time to build relationships through the appropriate allotment of workload credits to honor time is needed. Building capacity of non-Indigenous faculty wanting to weave Indigenous content into their courses respectfully means that faculty development and supports are enacted to sustains the insure protocols are followed. Decolonizing frameworks offer guidance to faculty, academics and the academy to insure local Indigenous content in curriculum and courses.

Ways of incorporating the aboriginal paraprofessionals into teambuilding efforts ${ }^{[6]}$ in a shared instruction in the classroom and the clinical settings between aboriginal and paraprofessional and health professional programs has showed promise ${ }^{[3,4]}$ Further, a successful collaboration would take the form of a blend of conventional western health care ideas and traditional healing practices. ${ }^{[2,6]}$ Having Knowledge Keepers in the classroom and practice so that students can have feedback on Indigenous Ways of Knowing and being 
in the context of the interdisciplinary framework application to health care issues and creative cultural strategies to engage Aboriginal Peoples in health promotion and prevention. Hands on cultural activities and practice of cultural safety is woven throughout the course. Course assignments are directed at practicing interdisciplinary engagement parallel to engaging with paraprofessionals, interdisciplinary team members, Knowledge Keepers and being mindful of the impacts of the health care organization's policies, procedures and governance structures. There is a gap in engaging with Indigenous communities to inform nursing curriculum to enact a decolonizing framework where nursing epistemology and ontology is informed by a two-eyed seeing approach. ${ }^{[4,5]}$ A two-eyed seeing ${ }^{[4,5]}$ approach shows promise to integrate traditional nursing epistemologies and ontologies with Indigenous ways of knowing and being. Engaging Indigenous communities through partnerships, honoring of protocols, reflexivity at the outset of course development enacts a decolonizing approach to inform curriculum and enriches pedagogical initiatives. ${ }^{[10]}$

\subsection{Two-eyed seeing}

The two-eyed seeing approach ${ }^{[3-5]}$ shows promise not only to embrace the western health pedagogies but also the academic institutions education program committee approval processes so they can concurrently be informed by Indigenous ways of knowing and being. The shared approach to recognize and integrate respective epistemologies and ontologies of western and Indigenous ways of knowing and being and other methodologies that incorporate new research approaches and community involvement and participation echoes the intent of a 'two-eyed seeing approach'. [4]

Two eyed seeing grew from the teachings of the late Mi'kmaw spiritual leader, Healer and chief, Charles Labrador of Acadia First Nation, Nova Scotia, especially with these words: "Go into a forest, you see the birch, maple, pine. Look underground and all those trees are holding hands. We as people must do the same." Twoeyed seeing is therefore, the gift of multiple perspective treasured by many Aboriginal Peoples. The phrase was coined when Albert [Albert Marshall] felt that audiences hearing Chief Labrador's word could benefit from additional encouragement toward the "it's us" consciousness of the "trees holding hands" For today's times, Two-Eyed seeing is a guiding principle for bringing together world views, different paradigms. ${ }^{[5]}$

A two-eyed seeing approach ${ }^{[4]}$ extends the nursing curriculum lens and challenges the traditional institutional academic processes of curriculum to follow protocols for aboriginal community engagement at the beginning of program and course development to insure that the Indigenous ways of being and knowing are honored and enacted within courses. Enacting Indigenous ways of being and knowing in a reflexive manner engaging partnerships with Indigenous communities through theoretical content of courses and through practice opportunities. Engagement of students should occur early in the nursing program engaging students through: local Indigenous cultural activities where Indigenous Knowledge Keepers share their wisdom; participatory experiences that depict the experience of colonization of Indigenous Peoples; involvement of indigenous Knowledge Keepers in consulting with students in nursing theory and lab practice areas to offer guidance and feedback on 'practicing cultural safety' in a safe environment. The partnership approach that respects the ethical responsibility of honoring ownership of Aboriginal Peoples knowledge insures sustainability of relationships, and authenticity of content of courses that are meaningful and responsive to current 'health status pulse' aboriginal communities. Utilizing a two-eyed seeing ${ }^{[3]}$ ontology along with an interdisciplinary collaborative approach gives student nurses insights into the realities of nursing practice in aboriginal communities.

\subsection{Integration of interprofessional competency frame- work}

Recently, researchers have shown that nurses who recently graduated from university programs that used interprofessional education perceived to a greater extent that their undergraduate training had prepared them to work collaboratively with other professionals in comparison with nursing students from other universities that did not integrate interprofessional education into their respective curriculums. ${ }^{[8]}$ Further, interdisciplinary approaches in Indigenous communities demonstrate community success and empirical evidence shows promise for the implications in positively impacting health through a creative, community based approach. ${ }^{[4,15]}$ The National Interprofessional Competency Framework ${ }^{[15]}$ is based on a review of the literature and is competency based that can guide interprofessional education and collaborative practice based on six competency domains are: interprofessional communication; patient/client/family/community-centered care; role clarification; team functioning; collaborative leadership and interprofessional conflict resolution. ${ }^{[15-17]}$ Engaging Indigenous nursing practice experiences at band level health centers to understand the role of policy, governance, health transfer, and respective roles of interdisciplinary and paraprofessional staff first hand. Observing the complexities of influence of organizational structures comparing health care organizations that have completed or are in the midst of health transfer compared to other organizations that rely on health authority or staffing agencies improves nursing

ISSN 1925-4040 E-ISSN 1925-4059 
practice experiences and prepares students for graduate nursing practice. Providing nursing student with immersion or consolidated nursing practice with para professionals, professionals working under a Board of Director's governance model which is often not discussed in theory or nursing practice environments. Further engaging students in community health placements working with non-profit aboriginal agencies offers further insights into the complexities of working within interdisciplinary collaborative teams. Integral to these approaches is acknowledging the role of policies within health care organizations ${ }^{[1]}$ and by extension those within respective universities in which Indigenous health nursing courses embrace protocol, community partnerships that honor knowledge keepers and ultimately the ownership of knowledge.

\section{Conclusion}

There is increasing evidence that interprofessional collaboration among professionals, aboriginal paraprofessionals and the community is desirable and builds capacity in northern, rural communities wherein the resources to sustain health care services is challenging. ${ }^{[6]}$ An interdisciplinary Indigenous health focus provides students the foundation to enact the decolonizing processes to facilitate equitable health services, engage effectively in interdisciplinary teams while understanding the role of health policy to improve Indigenous health status in Canada. This approach is unique to nursing and uses a holistic approach of two-eyed seeing and a decolonizing framework and challenges academics to shift their respective lens to engage aboriginal communities and student nurses in partnerships in the development of university courses. Further, student nurses were involved with community health forums that sought input from Indigenous Knowledge Keepers and community health members to define "what is Indigenous health?" and clarify "what is important for nursing students to learn?" In particular, students participated in the development of the course to facilitate future students' experiences of: explore interprofessional team building skills (i.e., professional and paraprofessional); knowledge of professions; patient centered care; and health care service policy when they take the course. Students will learn the impact of Indigenous culture on healthcare delivery and apply this knowledge through the development of an interprofessional health and healing presentation. The spirit of a respectful response to the final report of the Truth and Reconciliation Commission of Canada ${ }^{[1]}$ includes ninety-four interrelated Calls to Action this course embraces the interrelated calls to action and focuses in particular on two that are relevant to Aboriginal health initiatives and align with the university mandate and mission to advance Aboriginal, Global, Intercultural understanding. The Thompson Rivers University, School of Nursing has selected this course as a priority given its commitment to the Truth and Reconciliation Commission of $\mathrm{Canada}^{[1]}$ and ultimately to improve interprofessional collaboration, understanding of Indigenous ways of knowing and to promote the health and wellness of Indigenous peoples.

\section{CONFLiCTS OF INTEREST Disclosure}

The author declares that there is no conflict of interest.

\section{REFERENCES}

[1] Truth and Reconciliation Commission of Canada [TRC]. 2015. Calls to action. Winnipeg, MB: TRC. Available from: http://www.trc.ca/websites/trcinstitution/File/20 15/Findings/Exec_Summary_2015_05_31_web_o.pdf

[2] Jarvis-Selinger S, Ho K, Lauscher HN, et al. Social accountability in action: University-community collaboration in the Development of an interprofessional Aboriginal health elective. Journal of Interprofessional Care. 2008; 22(S1); 61-72. PMid:19005955 http://dx.doi.org/10.1080/13561820802052931

[3] Bourque Raymonde LL. Mâmawoh kamâtowin; coming together to help each other: honoring Indigenous nursing knowledge (Doctoral Dissertation). Dissertation University of Alberta, Edmonton, Canada. 2014.

[4] Marshall M, Marshall A, Bartlett C. Two-eyed seeing in medicine. In Greenwood, M., De Leeuw, S., Lindsay, N.M., \& Reading, C. (Eds.), Determinants of Indigenous Peoples' Health in Canada: Beyond the Social. Toronto, ON: Canada Scholar's Press. 2015. 17p.

[5] Bartlett C, Marshall M, Marshall A, et al. Integrative science and Two-eyed seeing: Enriching the discussion framework for healthy communities. In Hallstrom, L.K. \& Guehlstorf, N.P, \& Parkes, MW. (Eds) Ecosystems, Society and Health: Pathways through diversity, convergence, and integration. McGill-Queens University, Montreal: QU. 2015. 280-236.

[6] Educating Nurses to Address Socio-Cultural, Historical, and Contextual Determinants of health among Aboriginal Peoples. Canadian Association of Schools of Nursing. 2013.

[7] Williams B, Day RA. Context-Based Learning. In E. Nieginski (Ed), Teaching Nursing: Developing a student centered environment. Philadelphia, PA: Lippincott Williams \& Wilkins. 2007. 221-241.

[8] Munroe B, Boone M. Realizing potential: improving interdisciplinary professional/paraprofessional health care teams in Canada's northern aboriginal communities through education. Journal of Interprofessional Care. 2002; 16(2): 139-147. PMid:12028894 http: //dx.doi.org/10.1080/13561820220124157

[9] Purden M. Cultural considerations in interprofessional education and practice. Journal of Interprofessional Care. 2005; 224234. PMid:16096157 http://dx.doi.org/10.1080/135618205 00083238

[10] Health Canada [Internet], British Columbia Tripartite Framework 
Agreement on First Nation Health Governance [updated 2011] Available from: http://www.hc-sc.gc.ca/fniah-spnia/pub s/services/tripartite/framework-accord-cadre-eng.p hp\#a2

[11] First Nations Health Authority. Health through wellness: Nursing review. 2015. Available from: http://www.fnha.ca/what-we-d o/nursing-services

[12] Gerlack A, Sullivan T, Valavaara K, et al. Turning the gaze inward: Relational practices with aboriginal people informed by cultural safety. Occupational Therapy Now. 2014; 16(1): 20-21.

[13] Beckett A, Gilbertson S, Greenwood S. Doing the right thing: nursing students, relational practice and moral agency. Journal of Nursing Education. 2007; 46(1): 28-32. PMid:17302097

[14] Vukic A, Jesty C, Mathews Sr V, et al. Understanding race and racism in nursing: Insights from Aboriginal Nurses. International Scholarly Research Network. 2012.
[15] A National Interprofessional Competency Framework. Canadian Interprofessional Health Collaborative (CIHC). 2010. Available from: http://www.cihc.ca/files/CIHC_IPCompetencies_ Feb1210.pdf

[16] Wilhelmsson M, Svensson A, Timpka T, et al. Nurses' view of interprofessional education and collaboration: A comparative study of recent graduates from three universities. Journal of Interprofessional Care. 2013; 27: 155-160. PMid:23347287 http://dx.doi.org/1 $0.3109 / 13561820.2012 .711787$

[17] Blackstock S, Harlos K, MacLeod M, et al. The impact of organisational factors on horizontal bullying and turnover intentions in the nursing workplace. Journal of Nursing Management. 2015; 23 : 1106-1114.

[18] Malone JL, Stanley D. Community-based mental health initiatives in a First Nations Health centre: reflections of a transdisciplinary team. Pimat'siwin: A Journal of Aboriginal and Indigenous Community Health. 2013; 11(3). 